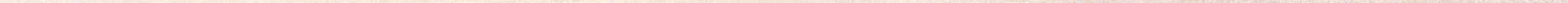




\title{
CRONOLOGIA NA COROLOGIA
}

\section{- A construção de uma perspectiva temporal}

\author{
PEDRO HENRIQUE CORRÊA DE ARAÚJO BARROS* \\ ROBERTO CÉLIO VALADÃO\%*
}

RESUMO A Geomorfologia, como tradicional subcampo do saber geográfico, prima, por essência, pelo caráter espacial dos fenômenos atrelados às dinâmicas inerentes da superfície terrestre. Entretanto, para compreender suas respectivas morfologias é obrigatório repertoriá-las, não somente no espaço, mas, fundamentalmente, através do tempo. Desde que o mundo deixou de ter a esguia e finita história proclamada pelas Sagradas Escrituras e debutou numa imensidão jamais imaginada, os estudos referentes à atuação processual foram catapultados a uma outra ordem de análise. Assim, o objetivo do presente trabalho é evidenciar que a perspectiva de tempo geológico fora historicamente construída e que os desdobramentos metodológicos que dela alvoreceram acabaram por balizar essa ciência natural, também, à luz dos estudos contingenciais, típicos de um campo essencialmente historicizado.

Palavras-chave Geografia. Geomorfologia. Tempo Geológico. Uniformitarismo.

\section{CHRONOLOGY IN CHOROLOGY}

\section{- Building a Temporal Perspective}

ABSTRACT Geomorphology, as a traditional subfield of the geographical knowledge, foregrounds, by essence, the spatial character of the phenomena conjoined with the inherent dynamics of the terrestrial surface. However, in order to comprehend its respective morphologies it is required that we compile them, not only in space, but, fundamentally, through time. Since the world dissociated itself from the fine and finite history proclaimed by the holy writ and opened up an immensity never conceived by man, the studies related to the processual performance were catapulted to another order of analysis. Thereby, the goal of the present work is to evidence that the perspective of the geological time was historically built and that the methodological outcomes arisen from it ended up determining that natural science, also, by the light of the contingent studies, typical of an essentially historicized field.

KEYWORDS Geography. Geomorphology. Geologic Time.Uniformitarism.

* Doutorando do Programa de Pós-graduação em Geografia, Instituto de Geociências. da Universidade Federal de Minas Gerais. E-mail: pedrohcabarros@gmail.com

*** Professor Titular do Departamento de Geografia da Universidade Federal de Minas Gerais. E-mail: valadao@ufmg.br 


\section{Introdução}

U m olhar panorâmico sobre a história das ciências modernas revela que preocupações acerca da ordenação espacial dos fenômenos sobrelevam-se, consideravelmente, se não de forma exclusiva pela chancela da Geografia e assentam-se, minimamente, sob formalismos afins da referida disciplina. Em outros termos, apesar de reconhecermos que a dúvida topológica é, quiçá, tão antiga quanto a história da humanidade, que o propulsar da ciência geográfica origina-se em consequência duma outra e singular trama conceitual, própria do transcurso do século XVIII para o século XIX na Alemanha, objetivamos esclarecer que, desde que a ciência moderna relegou ao objeto a centralidade ontológica, outrora posta no indivíduo, e passou a parametrizar a fluidez mundana exclusivamente no fenomênico, criou-se uma necessidade de se repertoriar os fenômenos, não somente em razão de suas inauditas, singulares e próprias condições, mas também pela surgente necessidade em se estabelecer conexões e relações entre eles. Assim, em consequência dessa laicização da Natureza, torna-se então tradição epistêmica e discursiva a imediata afinidade entre as prementes preocupações toponímicas dos fenômenos, os eventos e fatos e inquietações tão próprias do campo geográfico (SANTOS, 2002).

Nascida com um caráter fundamentalmente de síntese, enciclopédico, a moderna Geografia, em seu contexto de gênese, norteada por preceitos nitidamente empiristas, tem seus esforços direcionados ao inventário de lugares, ao levantamento dos recursos naturais existentes - as tarefas empreendidas por esse nascente campo disciplinar com perspectivas essencialmente corológicas, já que se preocupa com as dinâmicas concernentes ao espaço terrestre, sobretudo naquilo que indica os mecanismos e razões que tornam os ambientes naturais do planeta respectivamente distintos entre si. Nesse sentido, apesar do próprio conceito espaço sofrer com conotações epistêmicas próprias (NEWTON, I974; KANT, I989) por se tratar duma basilar categoria filosófica moderna, sua qualidade como objeto na ciência geográfica, no entanto, aparece como uma das poucas unanimidades dentro desse específico campo do saber. 
Com o natural decurso da ciência moderna, no seu porvir segmentado em variados campos do conhecimento, aquela ciência dos lugares, ou das meras localizações, ganha um pluralismo investigativo, ampliando e diversificando seu arcabouço teórico/ conceitual. Logo, a ciência da superfície terrestre se defronta, agora, com o engrandecimento da heterogeneidade e complexidade da organização espacial, ao reconhecer que dentro do todo, há, também, espaços específicos. Assim, o antigo espaço terrestre unitário e monolítico torna-se fragmentário e diversamente adjetivado.

Com esse emaranhar gnosiológico, a moderna Geografia viu-se, obrigatoriamente, na interdependência e numa consequente conexão com variadas disciplinas e com as demais ciências da Terra, já que, para dar conta de seu intricado objeto, ela não poderia tornar-se um campo de pesquisa fechado em si mesmo. A fim de desvelar relações e dinâmicas singulares do complexo e multifacetado espaço terrestre, o geógrafo, ao mirar a senda da espacialidade, lança-se por entre recortes analíticos da realidade, visando promover, em consequência da conjunção dessas pormenorizadas e fragmentadas compreensões, uma síntese das relações topológicas dos fenômenos. Assim, num claro posicionamento de interseção entre as ciências naturais e as ciências humanas, a ciência geográfica, ao primar por um caráter essencialmente horizontalizado do saber, lida com a compreensão da constituição do espaço geográfico, que é essencialmente produto da influência recíproca entre o labor humano sobre um quadro físico natural.

E justamente pelo fato de o meio físico, em sua extensão, alvorecer como receptáculo dos demais fenômenos e suas intrínsecas dinâmicas, surge, como condição sine qua non numa abordagem geográfica clássica a necessidade premente de se compreender e reflexionar sobre suas inatas relações. Daí o surgimento da Geomorfologia como ciência.

O compartilhar do mesmo radical etimológico denuncia, de antemão, seu similar caráter corológico. Contudo, ressalta-se, antecipadamente, que ela, diferentemente da Geografia, não investiga a espacialidade de qualquer conjunto de fenômenos. Tem, antes, por fundamento primário considerar e interpretar as distintas morfologias do relevo e suas espacialidades.

Aparentemente monótona e estática, a superfície terrestre apresenta-se, não obstante, de maneira extremamente dinâmica e multiforme. De natureza essencialmente ritmada, a dinâmica dos processos que imprimem mutações às morfologias de relevo é, comparativamente à puerilidade da vida humana, incessante e morosa, já que se trata de 
um mosaico multiforme de processos, contumazmente irregulares e de circunstâncias de atuação, majoritariamente, de baixa magnitude e frequência, isto é, não catastróficos.

Nesse sentido, o dinamismo do relevo, por vezes, cotidianamente imperceptível, evidencia uma atuação processual fragmentária e descontínua, diversamente distribuída e sincronicamente articulada, não somente no espaço, mas, sobretudo, no tempo. Logo, as paisagens, como um grande palimpsesto, impõem, permanentemente, muitos desafios à abordagem geomorfológica, visto que, apesar de seu objeto de investigação ser sobre as formas de relevo, sua análise recai, obrigatoriamente, sobre a periodização delas ao longo do tempo.

Desde que o mundo deixou de ter a esguia idade proferida pelas Sagradas Escrituras, esse cenário, já caudaloso, embaraçou-se ainda mais. A história das transformações do mundo, outrora compactada, finita e teleologicamente subordinada em poucos milhares de anos, numa perspectiva fundamentalmente cíclica e imanente, torna-se, paulatinamente, mais dilatada, contínua, extensa, unidirecional e caótica. Obviamente, essa mudança paradigmática, assim como ocorre nas demais ciências, em termos kuhnianos, não procedeu de maneira irrefletida e instantânea. Pelo contrário, as referidas mudanças se deram em razão de determinados fatores e condições que, amalgamadas no hoje, possibilitam compreender que para a ciência geomorfológica, o decifrar do tempo em sua amplitude é imperativo para se compreender as questões relativas à estruturação e dinâmica do espaço.

Em conformidade com o acima exposto, objetivamos, portanto, com o presente trabalho, explicitar de maneira preliminar, mas tão precisa quanto possível, como o desvelar do tempo profundo reordenou o saber concernente às dinâmicas intrínsecas da superfície terrestre, ao catapultar suas temporalidades a uma outra ordem de grandeza, não somente de vastidão dos eventos, mas, sobretudo, no que se refere à série temporal de acontecimentos, ao clarificar inauditas efetividades de suas atuações e, portanto, ao estabelecer e assumir que a crosta terrestre é produto de inúmeros e aleatórios ritmos de transformações. Assim, delinearemos, principalmente, com base nos principais preceitos da ciência geomorfológica, no que se refere à sua práxis, como essa nova perspectiva temporal induziu a uma emergente clarividência na abordagem geomorfológica, pois, sendo ela essencialmente escalar, seu trato demanda, a desconstrução duma ordinária e cômoda concepção de tempo humano e auxilia, igualmente, na tomada de consciência 
sobre as multitemporalidades intrínsecas ao modelado terrestre, competências essas tão caras e extremamente pertinentes à sustentabilidade e ao planejamento ambiental, questões urgentes e necessárias às nossas hodiernas sociedades.

\section{Do êfemero à infinitude: um mundo essencialmente dinâmico}

O tempo, como matriz que subjaz e periodiza a condição intrínseca de vida, se não ocupa lugar de destaque no pensamento humano, alvorece, pelo menos, como questão inevitável em nossas considerações existenciais, em sua vivência prática. Entretanto, conforme atesta Elias (20I0), as primárias parametrizações eram, pois, mais obtusas e menos exatas que nossas presentes construções, já que as demandas e necessidades dos povos primitivos eram escassas e pueris, em consequência de circunstâncias de vida essencialmente arcaicas. Por orientarem suas vidas em um modo quase nada inquisitivo, numa franca perspectiva contemplativa, as remotas sociedades tinham, nesse sentido, quando muito, apenas uma necessidade de periodização quase momentânea de suas vivências sociais. Orientavam-se, essencialmente, em referência ao permanente ciclo periódico das estações, bem como na observação dos movimentos cotidianos, mensais e anuais de alguns corpos celestes, haja vista a onipotência mitológica e o consequente obscurecer de seus interesses interrogativos.

À medida que as necessidades práticas de um caráter majoritariamente social demandaram certos e precisos ordenamentos da vida cotidiana - agricultura, pecuária e demais atividades - a determinação do tempo tornou-se cada vez mais ativa, no sentido de se saber claramente não somente acerca da ordenação e padronização do contínuo das atividades sociais, mas (e inclusive) o "quando" dos ritmos menos contínuos das transformações da natureza física dos fenômenos. Logo, a experiência temporal vai-se condicionando, paulatinamente, em um caráter impositivo e urgente, situação até então desconhecida.

E o que a historiografia nos mostra é justamente isso. Apesar de não exatas, o emprego de terminologias temporais alvorece desde Homero e Hesídio que, expressadas em seus poemas, demonstram as diferentes vivências que os homens experimentavam do tempo em diversas circunstâncias da vida. Esse pluralismo semântico vai ganhando vagarosamente, nos séculos vindouros, contornos mais precisos até atingir seu ápice 
em Aristóteles, quando, segundo Rey Puente (2010), o Estagirita rompe completamente a ligação entre o tempo e a eternidade, e passa, então, a ser repertoriado, segundo o agora, isto é, produto de um antes e promovedor de um depois.

Mesmo supostamente regidos por um cosmos supralunar incorruptível e constante, as consecutivas aproximações que os homens, historicamente, experimentaram com o mundo material, imperfeito e, portanto, mutável, fizeram as sociedades - gradativamente libertas de superstições e mitologias - encarar a realidade como um grande mosaico de sucessivos fenômenos físicos, dando ao tempo um caráter fundamentalmente linear, contínuo, sequencial. Por meio do progressivo desenvolvimento social, em consequência do estabelecimento crescente de uma integrada trama de processos relacionados à vida humana, notadamente a partir da época escolástica, a experiência da temporalidade pelas sociedades vai engrandecendo e complexificando tanto os símbolos temporais concebidos quanto as posteriores sínteses que deles surgiram, as pretéritas e elementares reflexões acerca da puerilidade da vida humana - tais como seu caráter irrevogável e o temor irremediável da morte - direcionando-nos, forçosamente, a questões mais amplas, isto é, as realacionadas à defluência periódica dos fenômenos físicos.

\section{1 - Da criação à finalidade: intempestivos processos, exígua existência}

Com o esvaecer da garantia mítica na regência das mudanças no ambiente, a figura humana fora catapultada a uma orgulhosa posição no mundo. Esse extremar ontológico ganha contornos explícitos na era medieval quando, por concepção, assumia-se não só que o planeta ocupara uma posição de destaque no universo, mas (e inclusive) que todo o domínio da natureza estava teologicamente subordinado ao homem e a seu destino eterno (BURTT, I983). Concebia-se, à vista do exposto, uma profunda e persistente confiança de que, pelo fato de o homem ser o fator mais importante e controlador do universo, a natureza existiria exclusivamente para seu benefício, ou seja, a natureza e sua criação dar-se-iam para além de seu mero deleite e do seu amplo uso; serviria, igualmente, para a instrução humana.

O homem medieval, como um ser ativo na aquisição do conhecimento, baliza, portanto, suas experiências sensoriais com o mundo de uma específica referência, qual seja, passa a contar a história do planeta conforme proclamada pela infalível con- 
sonância entre as palavras de Deus (os textos sagrados) e Suas obras (os objetos da natureza). Nesse sentido, a reconstrução cosmológica e da história do mundo baseavam-se num "parentesco graciosamente concebido entre homem, Razão e o Amor eternos" (BURTT, I983, p. I3), isto é, a proposição de fatos e eventos naturais promovedores das mudanças no mundo deveriam estar harmoniosamente concordantes com as Escrituras.

Amplamente praticado por pensadores da época, esse pressuposto preconizava que Deus, quando da constituição do mundo, fez as coisas certas da primeira vez e que, sob Sua ordem, as leis da natureza produziriam uma história apropriada que jamais demandaria uma posterior intervenção para rearranjos ou correções de um cosmos imperfeito (GOULD, I99I). A ciência medieval partiria, em consequência, de uma convergência entre razão e revelação, já que, a partir da razão, induzir-se-iam os mecanismos de transformação aos quais o planeta esteve submetido, numa franca teleologia das leis naturais.

Assim, a presente superfície terrestre, amplamente desordenada e confusamente ocupada por corpos, fora assumida como produto de uma abrupta conflagração mundial que modificou indistintamente a pretérita, regular e perfeita Terra, paraíso primordial do Éden. Em tempos ainda vindouros, o planeta, novamente consumido por um novo dilúvio, serenar-se-ia em uma nova superfície concêntrica, lisa e sem particularidades, para que Cristo, com seu reino, regesse o ecúmeno durante mil anos, até que a última e triunfante batalha contra as forças do mal ocorresse, e, após esse Juízo Final, os justos ascenderiam aos céus, e a Terra, não mais necessária como morada humana, tornar-se-ia uma estrela (FIGURA I). 
Tendo, pois, a degradação contínua como princípio transformador da história do planeta, o roteiro narrativo medieval sobreleva-se, essencialmente, em detrimento de um desmantelamento subsuperfícial do aplainado assoalho terrestre, cuja gênese remete à colmatação uniforme de sedimentos oriundos de uma rudimentar e global bacia oceânica. Essa degradação geraria interstícios em meio aos estratos sedimentares mais basilares outrora depositados e, com o subsequente colapso dessas camadas, a originária superfície lisa e monótona transformar-se-ia na crosta desordenada e irregular tal qual hoje a conhecemos (FIGURA 2). Assim, sendo os registros dessa dinâmica distintos entre si, mas finitamente determinados, eles atestariam não somente que o planeta fora exposto a sucessivos eventos, como também que os mecanismos básicos de suas dinâmicas eram de natureza essencialmente catastrófica.

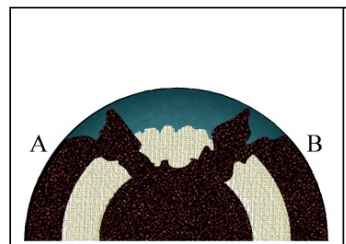

(I)

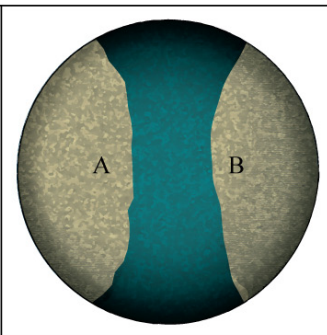

(II)

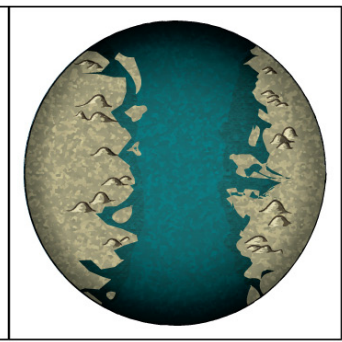

(III)

FIGURA 2 - Esquema explicativo acerca da natureza catastrófica da formação das morfologias da superfície da Terra. (I) - A Terra, com suas camadas concêntricas e de superfície plana teria, em um dado momento, a surgência de águas abissais, por meio de um cisalhamento de seu assoalho; (II) - Essas águas acabariam por inundar todo o planeta, (III) - Ao recuarem, as águas deixam uma crosta totalmente desorganizada, cujas bordas referem-se às modernas montanhas, e seus fundos, aos hodiernos oceanos. Adaptado de Gould (1991).

Além de dar suporte para as principais ideias sobre os processos e formação do mundo, as Sagradas Escrituras apresentavam, também, fundamentos para as estimativas da idade da Terra. Conforme ressalta Nogarol (20II), várias propostas foram lançadas acerca das supostas idades do planeta. De orientações mais concisas - poucas semanas, com dias com dilatadas durações - até outras que compreendem alguns poucos milhares de anos - as mais antigas datam o mundo de aproximados 6.000 anos - o que vale destacar, em consonância aos propósitos da presente discussão, independentemente de qual teoria seja mais precisa e verossímil do que outra, é o fato de que a era cristã reorienta, fundamentalmente, o problema do tempo, pois, por se tratar de uma religião que tem respectivas e precisas datas, eras e livros sagrados (REIS, 2009), ela acaba por estimular uma periodização da história do mundo. Ainda que com caráter essencialmente escatológico, a tradição cristã relegou ao conceito tempo uma fundamental perspectiva utilitária: ela usa esse conceito como estrutura que relaciona profusos eventos num mesmo enredo analítico. Assim, a eternidade, 
outrora posta no distinto mundo supralunar, fora relegada, agora, às questões de Deus, o criador absoluto de tudo, cabendo ao homem, portanto, interpretar contemplativamente os fatos no mundo da natureza, não somente no espaço, mas também no tempo.

\section{2 - Da estabilidade passiva ao equilíbrio dinâmico}

Em correspondência a uma série de novas práticas e ações investigativas sobre o mundo sensível, que buscaram confluir, cada qual em seu contexto ${ }^{\mathrm{I}}$, certa forma de experimentação empírica com o uso de uma pertinente linguagem matemática² ${ }^{2}$ a prevalecente tradição cristã fora superada. Essa ruptura³ impõe, ao mesmo tempo, além de uma nova condição cosmológica - a Terra deixa de ser o centro do universo para tornar-se meramente um dos muitos planetas que circundam um astro secundário nas fronteiras da galáxia -, uma nova referência ontológica, uma vez que a figura humana fora deslocada de sua orgulhosa posição de figura central da criação de Deus (CAPRA, 2002). Logo, não cabendo ao homem nenhum lugar elevado em uma teologia cósmica, ele deixa de ser o fator mais importante - e mesmo o controlador do universo - para tornar-se um mero espectador irrelevante dos efeitos do mundo real, um intruso em seus domínios (BURTT, I983).

Em termos práticos, aquela proverbial e inerente concepção que o pensador medieval tinha acerca da natureza, como algo subserviente ao seu conhecimento, intento e destino, turva-se em razão de ele passar a considerar a realidade existente e operante por si só e de forma independente, consciente de que a aspiração em se atingir alguma clareza a respeito da relação com ela deve, obrigatoriamente, partir da autoconsciência de reconhecê-la e admiti-la por ela mesma.

A produção do conhecimento passa, portanto, a ser produto não mais de uma interpretação contemplativa da natureza, mas de uma experienciação ativa com ela, numa relação de objetividade com objetos materiais e forças físicas que compõem o mundo, sendo ele definitivamente desprovido de qualidades imanentes. A observação paciente e direta da realidade desvela-se, progressivamente, como prática contumaz e amplamente pressuposta, alvorecendo, sobretudo, como novo princípio metodológico capaz de responder a uma antiga ordem de problemas. Tem-se, assim, uma drástica mudança de referência na tentativa de dar forma científica aos fatos e relações observados nas experiências sensoriais dos homens com relação ao mundo; pouco a pouco, os muitos
1 Kepler, Tycho Brahe e Galileu Galilei na astrono- mia, a matemática de Isaac Newton, a filosofia de René Descartes e a metodologia científica por Francis Bacon ilustram o método empíri- co traduzido em linguagem matemática.

2 "Newton não só encontrou um uso matemático preciso para conceitos, como força, massa, inércia, como deu novos significados a velhos termos como espaço, tempo, movimento" (BURTT, 1983, p. 24).

3 Conforme afirmam Burtt (1983) e Santos (2002), o processo de superação da cosmologia peripatética/ medieval para a cosmologia assentada nos preceitos da ciência moderna, apesar de amplamente tratada na literatura como produto de um súbito e clivoso ato, na verdade, reúne uma gama de ações e múltiplas atividades que ao longo dos séculos XVI ao XVIII criaram, paulatinamente, condições e possibilidades que viabilizaram esta mudança na concepção da imagem e concepção de Natureza. 
4 A diferença, segundo Burtt (1983), entre a filosofia escolástica e a moderna se traduz pelas respectivas categorias desenvolvidas pelos homens em seus tempos na tentativa de dar forma científica aos fatos quando da relação com o mundo, isto é, enquanto aquela tradição se baseava sobremodo nas categorias como substância, essência, matéria, forma, qualidade, subjazem na filosofia moderna os conceitos de tempo, espaço, massa, energia e outros mais. problemas dos fenômenos físicos, em vez de serem atribuídos a causas extrínsecas, irregulares e finalistas, passam a ser factualmente explicados, por se constatar que dependiam, na verdade, de leis fixas, invariáveis, eficientes. Trata-se, em resumo, de uma fluidez mundana, parametrizada, agora, exclusivamente, no fenomênico, quando a lida empírica sobrepõe, terminantemente, o apriorismo, bem como o princípio de autoridade e a exegese bíblica, ao liquidar racionalmente os conceitos e as categorias de análise que vigorosamente sustentaram a ciência peripatética e medieval4

À vista do exposto, as desigualdades morfológicas e suas irregulares fisionomias, há muito observadas na superfície, conteriam, portanto, em si mesmas, sinais evidentes de diferentes e sequenciais mudanças, já que o planeta, por não mostrar nenhum vestígio de um princípio, tampouco alguma perspectiva de um fim, atestaria que a Terra não se degradou em ruínas apenas naquelas poucas e certas vezes; pelo contrário, ao longo de sua história, efetuaram-se reciclagens dos produtos da erosão em uma permanente e vívida atuação processual.

Baseando-se, pois, numa lida empírica, o antigo saber sobre o planeta, fundamentado em obscuras proposições de convulsões globais, dilúvios e criações sobrenaturais de vida, numa franca mecânica telúrica, fora gradativamente substituído pela análise pormenorizada dos estratos que edificavam as paisagens. Eles, em suas mais diversas geometrias e conformações, testemunhariam que aquela única e presumida regra de deposição sedimentar - em consequência da precipitação integralmente horizontalizada e concêntrica de uma primitiva bacia oceânica global - apresentava-se, deveras, como uma perspectiva superada, pois as inconformidades desses estratos, bem como seus inclinados e assimétricos ângulos de contato indicavam um mundo em constante movimento, que se alterava progressivamente, numa dinâmica prolongada, e que não conduziria a propósito algum. Assim, à medida que se expandia o conhecimento e a instrução acerca das ciências da Terra, o racionalizar sobre uma simples geometria de horizontalidades sobre verticalidades demandava uma lista cada vez mais caudalosa de eventos que se incompatibilizava com a disponibilidade finita e fixa de tempo outrora proposta (FIGURA 3).

As inconformidades seriam, em consequência, a prova direta de que a história do nosso planeta inclui diversos ciclos de deposição e soerguimento, pois, por constituírem uma superfície fóssil, produto de processos erosivos, explicitariam uma dis- 


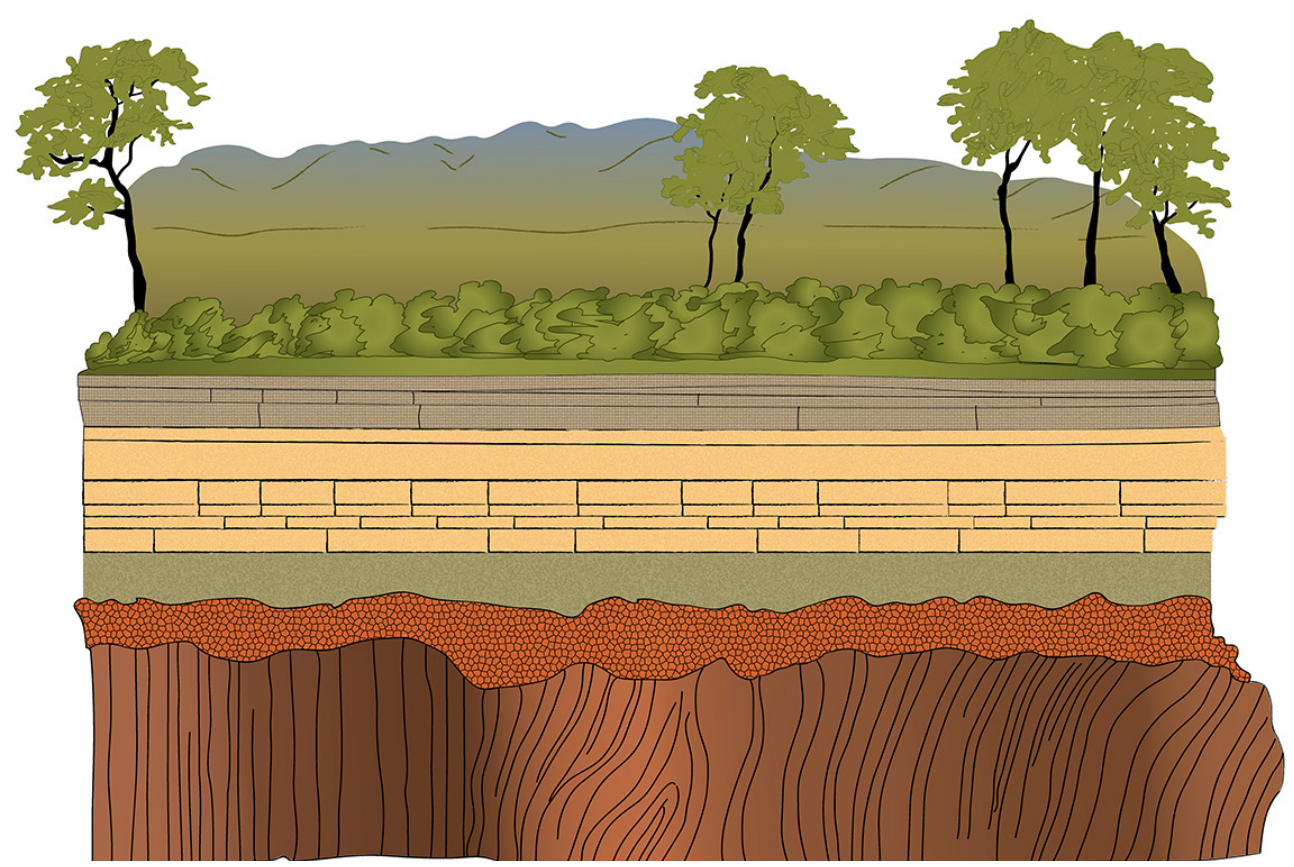

FIGURA 3 - Inconformidade que segundo a literatura especializada, despertou a ideia sobre a dinâmica do planeta. Fonte: Gould, 1991, p. 98.

cordância mineralógica/litológica referente a um hiato temporal, que distinguiria, portanto, dissemelhantes episódios de formação das rochas, dos solos. À única e pretérita concepção de dinâmica motriz responsável pelas mudanças ambientais - eventos catastróficos - adicionam-se, definitivamente, processos de intensidades e magnitudes outras, ao atestar-se factualmente que a atuação lenta e constante de cotidianas e comuns causas poderia também, quando estendida para um dilatado lapso temporal, produzir numerosos, se não todos, os efeitos geológicos apreendidos no mundo.

Assim, diametralmente oposta à perspectiva medieval, cuja acepção era de um planeta em franca e duradoura estabilidade passiva, a moderna visão propunha que ele estaria, à vista do exposto, na verdade, sob condições de um equilíbrio dinâmico entre forças antagônicas. A importância crucial desse novo referencial teórico é que dele decorre, com base nessa nova e singular evidência sobre os ritmos e dinâmicas dos processos atuantes e transformadores da crosta, uma original e inerente parametrização acerca da história da Terra. 
5 Adota-se, para os propósitos da presente discussão, a perspectiva popperiana de lei natural: "considero ser útil e fecundo considerar as leis naturais como sendo enunciados sintéticos e estritamente universais", ou seja, "para todos os lugares do espaço e do tempo (ou todas as regiões do espaço e do tempo)" (1975, p. 291). Nesse sentido, usamos essa concepção de lei natural a fim de atestar uma afirmação válida e aplicável a todos os objetos posicionados em todos os pontos do espaço e do tempo.

6 Charles Lyell, precursor das ideias uniformitaristas, fora, segundo Ody (2005), largamente influenciado pelo pensamento newtoniano. Assim, baseando-se em duas específicas regras acerca das causas dos fenômenos, expostas por Newton em seu Princípios matemáticos da filosofia natural (1987), Lyell propôs suas ideias acerca das uniformidades, expostas em seus três volumes do Principles of Geology (18301833). As regras de Newton são: Regra I - "Não se hão de admitir mais causas das coisas naturais do que as que sejam verdadeiras e, ao mesmo tempo, bastem para explicar os fenômenos de tudo"; Regra II - "Logo, os efeitos naturais da mesma espécie têm as mesmas causas" (Newton, 1987, p. 166).

\section{3 - Uniformitarismo e a Chancela Metodológica - adescobertado tempo geológico}

Elaborada por meio de eventos que não cessam em operar, a presente epiderme terrestre é produto de uma contínua e histórica atuação de processos que imprimem transformações em suas mais variadas morfologias. Tratando-se, portanto, não de compasso, mas sim de compassos processuais, as inconformidades da crosta evidenciam o notável caráter ativo do planeta. Com base na apreensão e observação desses particulares registros, o objetivo das investigações acerca da história da Terra passou, então, a buscar uma identificação do que haveria em comum entre eles, a fim de estabelecer explicações que reunissem esses fenômenos num padrão de atuação processual.

Em consequência da constatação de certas regularidades quanto às circunstâncias de suas atuações e na produção de seus correspondentes registros, as rochas e suas descontinuidades tornaram-se, em consequência, peças do tempo, já que, mesmo sendo entidades estáticas, elas reportariam, quando de suas análises, a contextos processuais e paleoambientais essencialmente dinâmicos e sequenciais. Nesse sentido, as observadas inconformidades e descontinuidades geológicas localizadas em específicos lugares e em determinadas épocas prestar-se-iam ao estudo de eventos gerais, pois, baseandose francamente em correlações causais, possibilitaram que as particularidades desses singulares eventos fossem extrapoladas, não só no espaço, mas sobretudo no tempo. Por outros termos, à medida que as preocupações investigativas foram distanciando-se das meras, ociosas e vãs especulações, tingidas pela teologia, fundamentando-se, essencialmente, nas observações empíricas de campo e nas derivações racionais dessas práticas, foi-se certificando que a natureza opera segundo leis naturais e que a amplitude do mundo material se traduzia em função de uma organização e de dinâmicas subordinadas a esse preceito.

Logo, ao se estabelecer um novo quadro determinístico da natureza, não mais pela mecânica teológica, mas pelo incessante atuar das leis naturais ${ }^{5}$, fundamentado pela experiência cotidiana com o mundo, a ciência moderna uniformizou, além dos processos, suas atuações e seus produtos correlativos. Assim, com base nessa esquematização do mundo sensível, instituiu-se, sob a rubrica comum da uniformidade, duas asserções metodológicas fundamentais às ciências em geral, sobretudo, às ciências da 
terra, quando da busca de leitura de mundo, sobre os marcos de sua transformação: a uniformidade das leis e a uniformidade dos processos.

Pressupõe-se, destarte, a invariância processual dos fenômenos naturais, tanto na sua forma de atuação quanto, consequentemente, de causa e efeito, isto é, chancela-se uma garantia ontológica que possibilita estender a inferência processual a um passado não observado, já que as mesmas causas atuantes no presente atuaram também em tempos idos, sob os mesmos mecanismos. Assim, as regularidades empiricamente desveladas no presente passam a ser consideradas, portanto, frequentes não só no espaço, mas também no tempo, já que descobertas as verdadeiras causas ${ }^{6}$ de um fenômeno, elas oportunizariam explicar toda uma classe de fenômenos, ou seja, explicar tanto os fenômenos que hodiernamente ocorrem quanto os que já aconteceram, ou até mesmo prever os que ainda se realizarão.

Em razão de a história da Terra não seguir qualquer vetor de progresso, com vistas a alguma inexorável direção, estando, pois, em um permanente estado de (des) equilíbrios sustentados, poder-se-ia, também, usar sua ordem atual para inferir seu passado. Firmando-se, então, numa uniformidade de estado, ao negar uma progressão nas transformações do mundo, o planeta teria, portanto, sempre o mesmo aspecto e se comportaria, aproximadamente, como agora. Assim, à uniformidade das leis e dos processos, adiciona-se a equitatividade das mudanças ao longo do espaço e do tempo, ao admitir que a Terra nunca fora, ao mesmo tempo, integralmente convulsionada. Catástrofes, caso ocorressem, seriam estritamente locais, tendo o mundo, portanto, um padrão de mudanças essencialmente contínuo, lento, invariável e gradual.

Esses pressupostos desaguam, obrigatoriamente, no estímulo de uma perspectiva de vastidão acerca da temporalidade mundana. As tradicionais narrativas sobre as dinâmicas ordenadas e previsíveis são inteligíveis a uma trajetória de um planeta jovem, cujo zeloso criador impregnou sinais claros de sua mente harmoniosa (GOULD, I99I), enquanto processos que obedecem a leis naturais, numa franca atuação contingente, paulatina, contínua e infinita, demandam uma outra ordem de grandeza e concepção, impulsionando, definitivamente, a história do mundo e suas transformações a uma outra perspectiva de dinâmica e atuação jamais imaginada7 .

7 A pesquisa de fósseis também amparou os estudos acerca do planeta e reforçou a ideia do tempo geológico. Em consequência de catalogações e meticulosas determinações da ordem dos diferentes conteúdos orgânicos presentes nos mais diferentes estratos, foi possível, portanto, estabelecer sucessões de ordens minerais. Logo, em detrimento de ausências, recorrências ou similaridades entre esses registros fossilíferos fortaleceu-se a ideia de uma vastidão temporal inerente à história do planeta. Outra forte evidência acerca do tempo geológico, amplamente mostrada pela literatura, são as considerações de Darwin sobre o caráter evolutivo das espécies. Para Darwin, os mecanismos responsáveis pelas alterações das espécies demandariam, obrigatoriamente, um longo e vasto lapso de tempo (MAYR, 2005). 


\section{Uma ciência natural historicizada}

Entre meados do século XVII até início século XIX, os conhecimentos acerca da crosta terrestre estavam heterogeneamente dissolvidos e despertavam interesse em diversos campos do saber. Numa era polimática, a história do planeta reuniu, assim, proposições daqueles que hoje se intitulam teólogos, arqueólogos, historiadores e linguistas (ROSSI, I984), além, obviamente, dos geólogos e geógrafos.

Mesmo que exposto de maneira preliminar, mas tão preciso quanto possível, tem-se que a constituição histórica do saber humano se deu por um processo que deslocou, paulatinamente, o sujeito pensante, ao recolocá-lo e redimensioná-lo como sujeito do conhecimento, num permanente movimento de renovação, não somente de concepção, mas, sobretudo, de sua relação com o objeto. Assim, conforme a construção discursiva deixava-se de pautar por um discurso justificador, elaborado por um observador-espectador que meramente contemplava e considerava o mundo do ponto de observação em que ele efetivamente se encontrava e se transfigurava - em consequência da laicização da Natureza - para adotar uma prática efetivamente explicativa, tendo na empiria a base de teste de afirmações feitas sobre a Natureza, rompia-se com pretéritos paradigmas, ao construir, progressivamente, um mundo novo nos interstícios das dificuldades do velho (SANTOS, 20I2). Nesse permanente deslocar do sujeito, a centralidade ontológica, que outrora era posta no indivíduo, fora, paulatinamente, transferida ao objeto, o que, com o surgimento da ciência moderna, fez assentar marcos fundamentais de delimitação, não somente de demarcação de pertinentes problemas, mas, sobretudo, de meios e modos de resolução desses problemas.

Erigida nos contrafortes da ciência moderna, a Geomorfologia sobreleva-se como o campo do conhecimento dedicado, primariamente, à consideração e interpretação das distintas morfologias do relevo. Sendo essas "esculpidas pela ação de determinado processo ou grupo de processos, estudar ambos pode ser o objetivo central desse ramo do conhecimento" (CHRISTOFOLETTI, I980).

Essa perspectiva científica da Geomorfologia está frequentemente associada ao paradigmático trabalho de Willian Morris Davis (I899), já que, por entre os reconhecidos limites e insuficiências dessa original proposição acerca da organização da crosta, tem-se um cabedal conceitual cuja força ainda reverbera nas práticas hodiernas da 
disciplina. A proposição de um relevo dinâmico, repertoriado, não mais apenas espacialmente, mas também temporalmente, induz a uma perspectiva processual que, se não inédita (vide GILBERT, ı887), é estimulada em Davis. Corporificado sob o status de teoria, o conhecimento acerca da crosta terrestre, inicialmente de caráter totalizante, experimenta um longo e contínuo progresso, cujo avanço teórico representa o quanto a Geomorfologia enriqueceu e se diversificou graças a contribuições coletivas no diálogo com as variadas ciências da Terra (COLTRINARI, 2000). Em resumo, conforme atesta Joly (I977), o estudo das formas de relevo engloba, fundamentalmente, não só a gênese e suas relações dentro do espaço, como a sua evolução ao longo do tempo.

Tendo os processos geomorfológicos uma natureza essencialmente físico-química, sendo regidos, portanto, pela invariância das leis naturais, a atividade de cognição acerca das dinâmicas da epiderme terrestre perpassa, inevitavelmente, à vista do que fora até agora exposto pelo descortinar das regularidades causais entre a atuação dos processos naturais contemporâneos e seus registros correlativos impressos na paisagem. Desveladas as leis e condições que governam as mudanças ambientais, em consequência da repetição de certas dinâmicas e respectivos registros, evidencia-se uma correlação estritamente direta entre eles, já que à atuação de determinados processos sempre se seguem determinados efeitos. Alvorecem, em consequência de uma leitura essencialmente monossêmica dessa parelha sequência geomorfológica processo-forma, as inferências e deduções sobre o passado histórico das formas da crosta da Terra.

Nesse sentido, apesar da Geomorfologia ser categorizada claramente como uma ciência natural, já que se interessa pela ordenação e sistematização de fenômenos do mundo físico, ela lida, contudo, fundamentalmente, com questões históricas. Mesmo não deixando de ter seus próprios marcos teóricos que lhe servem de fundamento para suas explicações, o saber geomorfológico, no entanto, apoia-se, substancialmente, em formalismos e princípios de outras disciplinas, tais como a química e a física, uma vez que, pelo fato de os processos que regem as transformações da epiderme terrestre obedecerem a leis naturais, o entendimento da histórica dinâmica da crosta, passa, portanto, necessariamente, pelo entendimento das causas que as operam e conduzem à formação das mais diversas morfologias da crosta.

Entretanto, o interesse de pesquisa em Geomorfologia converge, predominantemente, para a investigação da ordenação espacial e temporal de singulares morfologias. Logo, 
8 Um dos grandes desafios da Geomorfologia é, pois, equacionar, da melhor maneira possível, no caso, atribuir validade científica, às proposições acerca de dinâmicas próprias de um finito conjunto de dados experimentais com base nas nossas teorias, especulações, que contêm - pelo menos, potencialmente - um infinito número de predições empíricas. Mais especificamente no caso da Geomorfologia, pelo fato de, muitas vezes, seus estudos abarcarem cenários espaço-temporais com destacada abrangência e, portanto, com uma rarefação inexorável da quantidade relativa das informações empiricamente disponíveis, seja por sua complexidade e/ou inacessibilidade às condições iniciais do sistema, resta ao pesquisador, outorgar verdade científica a determinados arranjos teóricos, majoritariamente, por meio de raciocínios dedutivos e outras relações lógicas e não baseado na certeza empírica, o que atribui ao raciocínio geomorfológico um caráter, por vezes, mais probabilístico do que verdadeiro. apesar de azimutadas pelos princípios e circunstâncias gerais de atuação processual, a reconstrução da história dessa realidade particularmente aprendida perpassa, fundamentalmente, pelo reconhecimento de contingentes e, por vezes, singulares condições de elaboração dessas específicas formas. Os padrões gerais de explicação, ordenamento e dinâmica servem, assim, apenas para balizar nessa reconstrução histórica.

Tendo como objetivo premente a reconstrução evolutiva das formas de relevo, a Geomorfologia pulveriza interesses investigativos complementares a uma gama de classe de fenômenos. Não se atendo a explicações em conta somente de leis gerais, tampouco baseando-se meramente na análise de fatos particulares, a ciência geomorfológica busca amalgamar, em suas estruturas elucidativas, conjuntos de asserções regentes por leis gerais e circunstâncias contingentes de singulares eventos, quando da proposição de suas sentenças explicativas, conclusivas.

Nesse sentido, os procedimentos metodológicos típicos da Geomorfologia a particularizam em detrimento das demais ciências experimentais clássicas, pois, além de se alimentar dos universais preceitos causais quando da análise das paisagens, demandam, similarmente, a análise de narrativas históricas, que se baseiam largamente, na apreciação de múltiplas hipóteses explicativas, raciocínio analógico, valorização da interpretação de elementos contingentes, numa franca proposição explicativa de caráter verossímil ${ }^{8}$ ante a proposição de uma verdade última.

\section{Tu mudas! Mas como tu mudas?}

As formas de relevo, expressão espacial da superfície terrestre, compõem e configuram as mais distintas paisagens morfológicas. Essas, ao florescerem diante dos olhos, despertaram, ao longo da história humana, curiosidade e fascinação. Sendo o relevo terrestre percebido e vivenciado pelos homens, em suas múltiplas escalas, ele alvorece como recurso ou suporte da vida, fundamento do desenvolver da história, nos dizeres de Emmanuel De Martonne (I964).

Desde que o saber geomorfológico deixou de ser um conhecimento meramente corológico, preocupado unicamente com o reconhecimento, caracterização e mapeamento da superfície terrestre, e passou a se preocupar, também, com sua dinâmica 
evolutiva, houve, inexoravelmente, uma expansão e enriquecimento do arcabouço teórico-conceitual desse campo do saber. Miríades de épocas foram identificadas em consequência daquelas traduções acerca dos hodiernos registros de pretéritos eventos físicos, numa correlação causal das sucessões de fenômenos nos mundos animados e inanimados, materializando, portanto, ideias mais definidas e refinadas sobre a imensidão do tempo. A ciência do presente inquietava-se, cada vez mais, com dinâmicas de um vasto e abrangente passado.

Sabendo-se, pois, que o planeta muda - por si - e conhecendo os mecanismos que o conduzem a essas transformações - naturais e continuamente atuantes - faltava, portanto, compreender desde quando ele muda, isto é, saber acerca dessa imensidão do tempo.

Paradoxalmente às posturas dos clássicos catastrofistas, que, apesar de também reconhecerem nas inconformidades marcas temporais particulares na expressão de uma pretérita dinâmica ambiental, os uniformitaristas, no que lhes concerne, passaram a traduzir esses mesmos registros para além do literalismo empírico que aqueles praticavam. Assim, no lugar da rigidez interpretativa no processo de leitura direta das evidências geomorfológicas - não se aceitando que as transições abruptas de sedimentos e fósseis indicariam mudanças quase instantâneas de climas e faunas, mas revelariam momentos alternados de repouso e de desordem na história do nosso planeta - considera-se que as taxas de mudança seriam, comparativamente às catástrofes, mais lentas, graduais e constantes e que as transformações ocorreriam, portanto, passo a passo, ao longo de vastos períodos que, amalgamados, convergiriam em grandes efeitos.

Sob essa perspectiva uniformitarista, várias proposições acerca da abrangência da história da Terra foram feitas 9 . Desde metodologias indiretas, até as mais pormenorizadamente detalhadas, todas elas objetivam, com maior ou menor grau de acuidade, determinar a idade de formação do planeta, em consequência dos diferentes eventos que modelam sua superfície. Fundamentados nas correlações e superposições entre camadas geológicas, à luz de certos princípios de deposição, os métodos relativos possibilitam reconhecer os acontecimentos numa escala temporal de "antes e depois", de tal modo que se possam apenas ordenar os eventos. De caráter mais exato, os métodos absolutos, ao utilizarem princípios físicos da radioatividade, mensuram certa quantidade de tempo (anos) decorrida desde a ocorrência de um específico acontecimento, que pode ser a formação de um mineral, de uma rocha, de um fóssil. Apesar desses

9 Obviamente, os interesses sobre essa temática não se iniciam com a proposição das ideias uniformitaristas. Várias foram as tentativas feitas para desvelar esse intrigante problema: desde propostas baseadas nos escritos bíblicos - arcebispo Ussher estabeleceu uma idade de 5520 anos - até as mais corpulentas, tal como a de Kelvin, que, já em 1862, tentou estabelecer a idade do planeta pela observação da temperatura do Sol. Para mais detalhes, consultar Nogarol (2011). 
10 "Segundo Paulet (2002), um inevitável sistema de filtros se interpõe entre o indivíduo e o objeto observado. Um caráter único e original emerge, portanto, dessa relação indivíduo - paisagem. Baseada e centrada no bojo de valores individuais - referentes a singulares contextos socioculturais - e na própria relação pessoal que o observador sente com o mundo e ao longo dele, a porta de entrada das interpretações e percepções da realidade traslada e se molda pela sensibilidade que cada um traz consigo (material de fundo ou intelectual): idade, gênero, sonhos, planos, lembranças, aparato sensorial, valores, padrões de pensamento, crenças, experiências, emoções. Essas e outras experimentações vivenciadas no desenvolver da vida do indivíduo constituem um véu translúcido, o qual é transposto quando da leitura e análise de um objeto, de uma realidade" (BARROS, 2013). Nos termos de Kant (1996), tudo o que chega à consciência é profundo e completamente ajustado, simplificado, esquematizado e interpretado. métodos realmente lançarem luz a respeito da imensidão do tempo do planeta, eles ainda esclarecem pouco acerca das reais dinâmicas processuais, uma vez que essas técnicas apenas atestam a ocorrência de determinado evento, sem, contudo, estabelecer a duração efetiva de seus acontecimentos.

A prática geomorfológica serve-se, largamente, da empiria, com vistas a uma apropriação teórica de um desdobrar material, por meio de uma relação imediata. Como seu objeto é apreendido em decorrência do todo, como um fragmento, tem-se, pois, que a observação e elaboração do mundo geomorfológico se constituem por meio de uma prática escalar. Essa, para além de seu uso matemático/cartográfico ordinário, presta-se, igualmente, à representação qualitativa pertinente do objeto, ou seja, a definição de uma escala lida, além de uma grandeza métrica, que inclui, similarmente, parâmetros de atuação e complexidade dos fenômenos.

Cada recorte implica, portanto, certa delimitação de relações, fenômenos, fatos e, sobretudo, de abrangências espaciais e temporais que outro recorte não teria a mesma visibilidade e, mesmo que se tratasse de uma mesma escala, dificilmente esse recorte referenciar-se-ia sobre o sistema geomorfológico sob os mesmos aspectos ${ }^{\mathrm{Io}}$. Logo, cada definição de recorte do real procede em uma individualização, isto é, em uma elaboração autônoma, quando cada parte se emancipa de seu contexto e será, nesse sentido, medida por ela mesma.

Assim, ao se estabelecer a escala do ponto de vista puramente quantitativo, isto é, como a simples redução ou ampliação das variáveis espaciais alteradas sobre uma faixa ampla e contínua, perde-se, ou ainda, desfigura-se largamente seu caráter operacional qualitativo não hierárquico. Logo, quando modelados, os processos, outrora fragmentados de uma contextualização mais ampla, acabam por ilustrar, não somente uma ordinária quantidade, mas também uma qualidade de atuação e distribuição ao longo de um monolítico lapso de tempo e espaço. Em consequência, a tradução monossêmica produzida por meio de um estrito recorte arbitrário da realidade reduz forçosamente seu caráter sistêmico, ao estabelecer uma representatividade discreta aos processos geomorfológicos, sendo esses, sabidamente, de caráter contínuo.

As metodologias geocronológicas e as interpretações que delas alvorecem assumem uma visão estrita do uniformitarismo, isto é, homogeneízam o entendimento de dinâmicas inerentes à crosta terrestre, já que considera, indiferentemente, sob a égide 
de processos, fenômenos sabidamente de naturezas diversas - contínua e discreta - ou mais especificamente, eventos de ocorrência gradual, episódica ou catastrófica. A distinção entre a qualidade dos fenômenos reflete não apenas a ocorrência e natureza processual (frequência), mas, sobretudo, suas respectivas capacidades e competências (magnitude) em mobilizar material quando de suas atuações - características que estão intimamente ligadas às circunstâncias de se gerar ou não registros correlatos. Logo, quando modelados, os processos acabam por ilustrar uma ordinária e instantânea quantidade e qualidade de atuação e distribuição ao longo de um monolítico lapso de espaço e sobretudo de tempo.

Em termos práticos, objetiva-se destacar que os processos variam espacialmente - um processo que ocorre aqui, não necessariamente ocorrerá acolá - e apresentam, igualmente, um sincretismo e um desarranjo entre os tempos de ocorrência e a efetiva produção de suas materialidades (DOTT, I983), ou seja, nem sempre o evento mais duradouro e gradual é responsável, obrigatoriamente, por uma materialidade de registro mais evidente e manifesta quando de sua análise, sendo, também, verdadeiro descartar sua antítese - que o evento mais violento e frequentemente mais breve necessariamente deixará um registro mais descontínuo e menos perceptível (FIGURA 4). Ademais, cabe ressaltar ainda que a transição entre as descontinuidades dos estratos, frequentemente atribuídas como meras inconformidades, pode representar, efetivamente, em questão de escala temporal e de dinâmica paleoambiental, importâncias e abrangências francamente desconsideradas, devido a sua esguia materialidade, que porventura pode ocultar, paradoxalmente, um intervalo de tempo superior àqueles efetivamente corporificados. Nesse sentido, os vazios de/nos depósitos passam também a revelar uma importância acerca da dinâmica evolutiva de uma paisagem, frequentemente inimaginada e deveras desconsiderada,

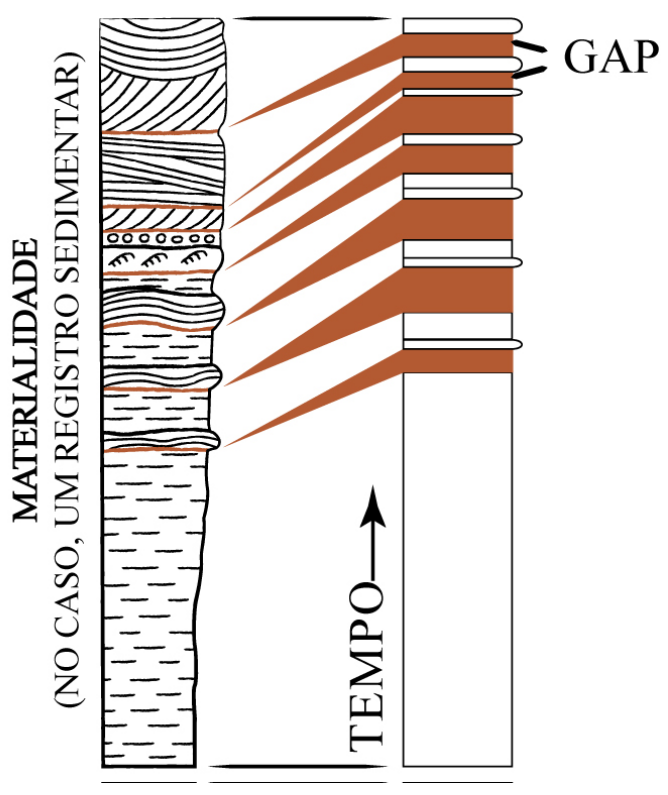

FIGURA 4 - Modelo hipotético para enfatizar as variâncias e disparidades entre a materialidade dos registros - suas espacialidades - e a efetividade de tempo para suas produções. Destaca-se que a materialidade de um registro pode, por vezes, não representar, efetivamente, o tempo total de atuação do respectivo processo que a produziu. Assim, processos podem atuar durante determinado período, mas seus marcos geológicos referem-se, na verdade, apenas a um ínterim dentro de uma efetiva e mais ampla duração. Ademais, evidencia-se, igualmente, a quantidade de tempo que as discordâncias (GAP) entre os estratos podem revelar em relação à evolução de uma paisagem. Apesar de frequentemente pouco representativas materialmente, elas podem expressar, contudo, uma quantidade de tempo na evolução da paisagem mais dilatada e complexa do que a concretude dos registros efetivamente representam. Adaptado de Dott (1983). 
pois, quando (des)percebidos em campo, frequentemente cedem sua grandeza interpretativa face à sua diminuta espacialidade (DOTT, I983).

Em conformidade com o que foi discutido, quando a análise de um sistema geomorfológico passa por um entendimento, meramente por meio das propriedades de modelos físicos, de traduções puramente monossêmicas dos registros, como, majoritariamente, a Geomorfologia vem experimentando, percebe-se claramente que esses dados obscurecem, paradoxalmente, aquilo que buscam representar, isto é, a variabilidade e imbricamento do natural decurso dos processos geomorfológicos, já que mensuram um determinado instante contido num dinâmico e mais dilatado evento.

Assim, ao considerar os registros geológicos e geomorfológicos, com suas respectivas e singulares descontinuidades e inconformidades, é mister concebê-los como sistemas complexos de análise (HARRISON, 200I), já que são resultados de uma profusão de fatores, eventos e processos em uma contínua, incessante e plural atuação. Assim procedendo, descontrói-se efetivamente aquela dual, maniqueísta e mutuamente excludente visão acerca da evolução do globo preconizada pelos "tradicionais" catastrofistas e pelos "revolucionários" uniformitaristas. Admitindo-se, pois, um caminho intermediário que nem somente assuma o literalismo empírico, tampouco a invariância de substância e estado do planeta, num eterno e vagarosíssimo alterar, abrem-se amplos caminhos para assumir ciclicidades relacionadas à atuação de certos fenômenos, mesmo dentro de um cenário inexorável de perpetuidade, assumindo que o planeta tem, possivelmente, uma origem poligenética.

\section{Considerações finais}

Preeminentes e multifacetadas necessidades posicionaram, distintamente, ao longo da história, diferentes homens e sociedades perante uma mesma realidade material. Independentemente da escala de perspectiva ou corte adotados para reflexão, objetiva-se realçar que um agregado de respostas demarca um conjunto de perguntas, isto é, aquele somente existe em conformidade denominativa com esse. Parte-se, assim, do ponto que o conhecimento e suas variadas matizes referem-se, essencialmente, à heterogeneidade de aspectos de uma mesma e única realidade. Não há, portanto, 
múltiplas realidades, infinitos mundos, tão numerosos e respectivos quanto o número de ciências, cientistas. O que se tem, e interessa o destaque, é uma dessemelhança na aquisição de respostas, isto é, que existem sim singulares apropriações e referenciais quando da apreensão entre sujeito e objeto, ou seja, de compreensão, por meio de técnicas, discursos, práticas, que se pulverizam em referência de uma cosmologia aludida a uma certa sociedade, num respectivo lapso temporal.

À medida que a vida das sociedades demandou ao homem o emprego cada vez maior de sua inteligência na tomada de consciência, a fim de confrontar suas convicções com o mundo físico, ele passou a se deparar, por meio de sucessivas aproximações com o acaso, com uma abertura de horizontes e com a diminuição ao apego à garantia de um controle mítico na regência das mudanças no ambiente. Isso se traduziu na busca pela compreensão, do máximo possível e da melhor maneira, tanto em extensão quanto em profundidade, daquilo que se pretende apreender do mundo: a necessidade do saber - traço essencial do ser racional - que exprime a autêntica grandeza e finalidade do espírito científico.

Assim, aquelas indagações diversas acerca da configuração e da história do planeta, alicerçadas em mistérios distintivos que apenas tangenciavam os limites da paisagem e das morfologias observáveis, sem, contudo, implicarem uma compreensão efetiva da realidade, foram, paulatinamente, sendo substituídas por explicações cada vez mais baseadas em práticas mais cautelosas e precisas de observação, experimentação e reflexão.

Numa convergência de esforços aparentemente díspares, a Geomorfologia alvorece na intercessão daqueles saberes preocupados em estabelecer os padrões gerais do funcionamento dos permanentes eventos e leis e de outros, por lidar diretamente com realidades que se sobrelevam por meio de eventos singulares e contingentes, numa perspectiva francamente unidirecional, histórica.

Desde que a história do planeta deixou de ter a esguia, finita e teleológica história proclamada pelas Sagradas Escrituras e debutou uma vastidão de tempo, fundamentalmente em razão de uma singular perspectiva de atuação processual, houve, inexoravelmente, uma reordenação acerca do entendimento dos eventos e de suas atuações. O modelado de determinada forma e sua abrangência geográfica passaram, então, a ser intrinsecamente relacionados às tipologias de processos atuantes, bem como à duração desses sobre o recorte espacial analisado. Sendo reconhecidamente produto 
de momentos alternados de repouso e de desordem, as discordâncias geológicas e as abruptas formas de relevo informariam, assim, que a superfície do planeta está num permanente movimento.

Ao que se propõe a ciência geomorfológica - o estudo da morfogênese das paisagens e sua evolução morfodinâmica, ao longo do tempo - grandes desafios se apresentam e são postos ao olhar do pesquisador, uma vez que identificar, no estado atual da arte, na maioria das vezes precário (SAADI, I998), o limiar das verdadeiras influências dos processos sobre as formas, não se apresenta e tampouco se configura como tarefa simples e óbvia. Embora os diversos processos tenham se sucedido no passado geológico e deixado singulares e respectivos vestígios no atual modelado, nem sempre esses produtos preservaram-se na sucessão dos eventos. Em razão das atuações processuais desenvolverem-se numa ampla e variada escala de espaço e de tempo, a abordagem geomorfológica, inevitavelmente, apresenta uma incompletude crônica dos registros desses processos, já que, por terem um caráter fundamentalmente sequencial - algumas vezes de ocorrências quase concomitantes - a sobreposição e consequentes retrabalhamentos de seus indícios acabam por tornar suas materialidades escassas; ocasionalmente, inexistentes.

Assim, sabidamente multifacetados, os processos que imprimem transformações na paisagem, ao tomarem centralidade investigativa nos relacionados à crosta terrestre, conduzem a uma necessária clarividência de suas efetividades, dentro de respectivos lapsos de espaço e, sobretudo, de tempo. Ou seja, suas existências passam, obrigatoriamente, a depender não somente dessas suas efetivas ocorrências, mas também da pertinência prospectiva de suas existências, já que, ao se aportar o fenômeno naquilo que ele empiricamente concede ao observador, isto é, sua cartografia, medições, cálculos, tudo feito, supostamente, sobre bases seguras e insofismáveis da razão, o sujeito, por vezes, o faz de modo intuitivo e não reflexivo, ao desconsiderar que o corte inicial de sua apreensão é, obrigatoriamente, de concepção e consideração sobre a pertinência escalar do fenômeno. Logo, mesmo que a evolução das paisagens esteja estritamente relacionada a meras causas químico-físicas - afinal, existem na natureza inorgânica processos que tendem a um fim e se devem simplesmente à operacionalização de leis naturais, tais como a gravidade e leis de termodinâmica -, o emprego da estrita visão mecanicista da causação acaba por ofuscar, contraditoriamente, aquilo que de mais rico a análise geomorfológica oferece: pluralidade de processos e suas eternas e plurais recorrências. 
Nessa perspectiva, os fatos, os dados que oportunizam a formulação e articulação conceitual são apenas elaborações lógicas que desempenham a função de representar a existência de um ente real no campo do pensamento. O reconhecimento do fenômeno alvorece em razão não apenas de sua ocorrência, mas, fundamentalmente, de uma "consciência do perceber" aquilo que interessa, isto é, estruturam-se condições de reconhecer a lógica dos fenômenos com base nos fenômenos da lógica. A condição existencial não se encerra na materialidade de uma realidade dada, posta, mas conforma-se, sobretudo, em estreita relação de uma proposta de apreensão e reconhecimento de uma existência no e por meio do raciocínio, do pensamento.

Por consequência, diferentemente da análise das demais ciências naturais, a mudança da escala de análise geomorfológica implica, obrigatoriamente, em transformações qualitativas não hierárquicas e dificilmente transferíveis, que, quando explicitadas, referem-se, notadamente, a particulares condições.

\section{Referências}

BARROS, P. H. C. A. Controvérsias geomorfológicas: dialética entre teoria e produção do conhecimento - as múltiplas perspectivas do pensar e fazer geomorfologia. 2013. I4O p. Dissertação (Mestrado em Geografia) - Instituto de Geociências, Universidade Federal de Minas Gerais, 20I3.

BURTT, E. As bases metafisicas da ciência moderna. Brasília: Editora UnB. I983. 269 p.

CAPRA, F. O Ponto de Mutação. São Paulo: Editora Cultrix. 2002. 477 p.

CHRISTOFOlETTI, A. Geomorfologia. 2 ed., São Paulo: Ed. Edgard Blücher Ltda., I980. I86 p.

COLTRINARI, L. Geomorfologia: Caminhos e perspectivas. Revista Brasileira de Geomorfologia, Ano I, n. I, p. 44-47, 2000.

DAVIS, W. M. The geographical cycle. Geographical Journal of the Roya Geographical Society, v. I4, p. 48I-504, I899.

DOTT, R. H. JR. I982 SEPM Presidential Address: Episodic Sedimentation--How Normal Is Average? How Rare Is Rare? Does It Matter?.Journal of Sedimentary Research, v. 53 , n. I, I983. 
ELIAS, N. Sobre o tempo. Rio de Janeiro: Zahar. I998. i65 p.

GILBERT, G. K. Land sculpture in the Henry Mountains. US Geography and Geology Survey of the Rocky Mountain Region. I887. 214 p.

GOULD, Stephen Jay. Seta do tempo, ciclo do tempo: mito e metáfora na descoberta do tempo geológico. São Paulo: Companhia das Letras, I99I. 22I p.

HARRISON, S. On reductionism and emergence in geomorphology. Transactions of the Institute of British Geographers. v. 26, n. 3, p. 327-339, 200I.

JOLY, F. Point de vue sur la géomorphologie. Annales de Géographie. T.86, n. 477, p. 522-54I, I977.

KANT, I. Crítica da razão pura. São Paulo: Nova Cultural, I996. 5II p.

LYELL, C. Principles of geology. 3.v.. London: J. Murray, I830-I833. Disponível em: http:// www.esp.org/books/lyell/principles/facsimile/contents.htm. Acesso em: outubro de 2015 .

MARTONNE, E. de. Tratado de geografia física. Barcelona: Juventud, I964. 520 p.

MAYR, E. Biologia, ciência única: reflexões sobre a autonomia de uma disciplina científica. São Paulo: Companhia das Letras, 2005. 266 p.

NEWTON, I. Princípios matemáticos da filosofia natural. São Paulo: Abril Cultural, ı987. $238 \mathrm{p}$.

NOGAROL, F. Revendo o debate sobre a Idade da Terra. 20II. IIo p. Dissertação (Mestrado em Física) - Instituto de Física, Universidade Federal do Rio de Janeiro. Rio de Janeiro, 20II.

ODY, L. C. Teoria e história na geologia. 2005, I05 p. Dissertação (Mestrado em Filosofia) Departamento de Filosofia, Universidade Federal de Santa Catarina. Florianópolis, 2005.

PAULETT, J.P. Les représentations mentales em géographie. Oaris, Anthrops, coll. Géographie. 2002. 152 p.

POPPER, K. Conhecimento objetivo: uma abordagem evolucionária. Belo Horizonte: Itatiaia/São Paulo: Edusp., I975. 394 p.

PUENTE, F. R. Ensaios sobre o tempo na filosofia antiga. São Paulo: Annablume, 20 o. I68 p. 
REIS, J. C. História, a ciência dos homens no tempo. Londrina: Eduel, 2009. 254 p.

ROSSI, P. The dark abyss of time. Chicago: University of Chicago Press, I984. 354 p.

SAADI, A. Modelos morfogenéticos e tectônica global: reflexões conciliatórias. Geonomos, v. 6, n. 2, p. 55-63, 1998.

SANTOS, D. A reinvenção do espaço: diálogos em torno da construção do significado de uma categoria. São Paulo: Editora UNESP, 2002. 2I7 p. 